\title{
ON THE PREPARATION OF COCCIDAE FOR MICROSCOPICAL STUDY.
}

\author{
By E. E. GREEN.
}

\section{Introductory Notes.}

Having been asked by several correspondents to describe the best method of preparing Coccidae for critical study, I have thought it might be useful to publish an account of the technique that I have adopted in my own work. I do not set it up as being the best method, as I have not experimented to any extent in other directions; but I have gradually arrived at a procedure that appears to produce satisfactory results which compare favourably with examples of mounting that I have received from other working entomologists. I am, however, confident that useful modifications and improvements could be effected by anyone conversant with the processes employed in modern laboratories. I must also confess that I work largely by rule of thumb and have not reduced my processes to exact measures of time and quantities. I find, indeed, that the essence of success depends upon minute variations in the treatment employed-to be learned by actual experience alone.

\section{Appliances and Reagents.}

I will first give a detailed list of the appliances and reagents that I have found necessary or convenient :

Any good compound microscope, with modern objectives.

A dissecting microscope (preferably an erecting binocular).

An Abbe-Zeiss camera lucida.

A reliable stage micrometer.

Fine-pointed forceps.

Small scalpels.

Dissecting scissors.

Two or three fine camel-hair brushes. 
Some "snipe-points" (the terminal feather of a snipe's wing) mounted in small porcupine quills.

Setting needles. These should be the smallest and finest obtainable.

A small (narrow) section lifter. A piece of stout silver wire, hammered flat at one end and turned up at a slight angle, serves the purpose admirably.

Evaporating dishes (2 $\frac{1}{2}$ in. diam.).

Several flat-bottomed watch glasses.

Short test-tubes (1 in. diam.).

Excavated glass blocks. These may take the place of the watch glasses, as they are most useful for the reception of such reagents as oil of cloves, distilled water and various strengths of alcohol, in which the objects have to be steeped for various periods. They will stand steady on the stage of the dissecting microscope.

Glass pipettes with rubber teats.

A small glass table, with a mirror below, is of great convenience when transferring objects from one medium to another.

The following reagents will be required:

A strong solution of potassium hydrate (liquor potassae).

Alcohol, $70 \%, 90 \%$, and absolute.

Fuchsin (acid), strong aqueous solution.

Picric acid, saturated solution in alcohol.

Glycerin, dilute.

Oil of cloves.

Canada balsam, dissolved in xylol.

Distilled water.

\section{Preparation and Mounting of Specimens.}

Coccidae do not necessarily require any prolonged process of preliminary preparation. They may be treated in the fresh condition without any difficulty. On the other hand, material that has been kept in alcohol or other liquid preservatives, or that has remained dry for many years, will respond to treatment with complete success-provided that it has not been allowed to become mite-eaten or infested with fungus.

Naked species, such as Lecanium, are the simplest subjects and may be best utilised to illustrate the process. The general procedure is the same for all Coccidae; but slight modifications (to be noticed later) will be necessary in particular cases. 
Let us suppose that we have some dried leaves or twigs infested with a species of Lecanium. Detach a few of the insects by means of a needle or fine scalpel, taking care not to injure the margin in so doing. Select examples of different stages of growth, and take more than will be actually necessary for the final mount. Some of them are sure to be imperfect and may be discarded during the later stages of the preparation. Place the selected specimens in a small evaporating dish, together with a tiny fragment of pumice stone (to prevent too violent ebullition). Add about two teaspoonfuls of strong potash solution and heat over a spirit lamp for from two to five minutes, agitating the vessel slightly and regulating its distance from the flame so as to keep the liquid simmering rather than actively boiling. If it is necessary to prepare several different species at the same time, specimens of each mav be isolated in small test-tubes (with the requisite amount of potash), plugged with cotton wool and placed erect in a small saucepan containing water, the whole being boiled together. The specimens must be examined at intervals and removed so soon as they begin to show signs of clearing. The right moment can only be learned by experience. If not treated long enough, there will be subsequent difficulty in removing the contents of the body. If treated for too long a time, the cuticle will become too tender and will tear or break up during subsequent manipulation.

During this process, note any colour given off by the objects. Certain species colour the liquid pink--or even crimson; others give off a greenish, brownish, or inky stain. A knowledge of such characteristics may be of assistance in differentiating between closely allied species.

Remove the prepared specimens, by means of the section lifter, to distilled water. Here, by a process of osmosis, further clearing will take place and part of the contents of the body will pass out into the water. I find it convenient to leave the objects in this medium for 24 hours, and I use the excavated glass blocks for their reception.

At this and all subsequent stages care must be taken to label the specimens in such a manner that they may be identified with the material from which they have been taken. This label should be transferred from vessel to vessel at each subsequent transference of the specimens. Failure to observe this precaution may lead to most unfortunate mistakes.

Before further treatment, note the form of the insect which will often have become distended to its fullest extent, when it may show characters that will be lost under subsequent compression. For instance, the lateral tentacular processes characteristic of the living 
Diaspis boisduvallii usually disappear entirely when mounted in balsam. The peculiar form of the Tachardia insect is best shown (and figured) at this stage.

It should also be noted whether the bodies contain well developed ova or embryos. The presence of such will settle conclusively the stage of the insect, in doubtful cases.

On the following day the specimens should be transferred to clean water, when the remaining contents of the body may be easily removed by manipulation with fine needles, assisted by the mounted snipe feathers. If the body is not already ruptured, a small opening should be made at one point, through which the liquid contents may be gently worked out. Small aggregations of wax, fatty globules, or partially solid matter may be removed by inserting a fine point through the artificial aperture.

The specimens are next transferred to and washed in $70 \%$ alcohol for a few minutes. They are now mounted temporarily on a glass slide in a drop of dilute glycerine, under a glass cover slip, for preliminary examination. After which, a few drops of fuchsin solution are run in with a pipette, and the slide is put by for another 24 hours.

Then add a few drops of picric acid solution and leave for five or ten minutes, to fix the stain.

Remove the cover glass; flood the slide with alcohol, to redissolve the partially crystallised picric acid, and transfer the objects to a bath of $70 \%$ alcohol, where the glycerine and superfluous stain can be washed out, together with any small fragments of the body contents that may have been overlooked during the earlier process. Such omissions can now be readily detected, as they will have absorbed a deeper stain.

When the removal of the stain has proceeded to the right point, the objects may be washed in absolute alcohol, preparatory to their removal to a bath of oil of cloves, though I have not found any ill effect following upon their direct transference from $70 \%$ alcohol. They may be allowed to remain in the oil for about 10 minutes, after which they are finally mounted in canada balsam.

If the same receptacles and media are used on subsequent occasion great care must be taken that every specimen has been removed. Confusion and erroneous determinations have occasionally arisen through the accidental inclusion in the finished mount of one or more specimens inadvertently left over from a previous operation.

After arranging the objects neatly in the centre of the slide, I place a sufficiency of balsam on the underside of the cover glass and lower it gently un to the specimens. I used, at first, to find that the balsam, 
when spreading itself under the cover glass, would disarrange my neatly disposed specimens, and even carry some of them away to the extreme margins. I now prevent this inconvenience by pressing the objects on to the glass with a small piece of thin smooth blotting paper. This absorbs the remaining oil of cloves and makes the objects adhere closely to the glass. Before adding the balsam and cover glass, the mount should be examined for the removal of any small fibres that may have detached themselves from the absorbent paper. Several specimens should be mounted on one slide, some showing the dorsal and others the ventral surface uppermost.

When dealing with strongly convex species, it is often advisable to slit the dorsum, as otherwise it will not lie flat on the slide. In such cases the venter should be separated from the dorsum and disposed so that the two surfaces can be examined side by side.

Species that are densely coated with wax, such as Ceroplastes, should have the waxy covering removed before the insect is boiled in potash. This can usually be done with a fine scalpel, without injuring the insect; or the wax may be dissolved in carbon bisulphide. Boiling in oil of cloves will have the same result.

The larger species of Monophlebus and allied genera are often so dense that satisfactory mounts cannot be made of the complete insect. It is better to divide them horizontally, separating the venter from the dorsum completely. If the insects have been preserved in alcohol, this section can be effected before boiling in potash. But, with dried examples, it is necessary to boil them for a short time, until the skin is softened, before attempting the operation. The object is then replaced in the potash and boiled until the two halves come apart and the soft inner tissues separate from the derm, leaving the latter quite clean.

The species of Tachardia (lac insects) are embedded in dense resinous gum which may be softened or completely dissolved by immersion in strong alcohol, before treatment.

Coccidae of the family Diaspidinae are concealed beneath composite scales consisting of the larval exuviae supplemented by secretionary matter. To obtain the insect itself, the scale must be lifted or turned over when the creature will be found either free or lying in the hollow of the overturned scale. If there is any difficulty in extracting the insect, the whole scale may be boiled in potash, when the secretionary matter is decomposed and the insect and pellicles freed. Some of these pellicles should be stained and mounted with the insect itself, as they often afford useful characters for the differentiation of closely allied 
species. In the absence of male puparia it is often difficult to decide whether a certain species should be included in the genus Aspidiotus or Diaspis. Examination of the larval and nymphal pellicles of the female will usually decide this point, for in Aspidiotus the dorsal half only of the pellicle is present in the scale, whereas in Diaspis the venter remains attached and will be found beneath the posterior extremity of the pellicle.

In the genera Aonidia, Fiorinia and Leucaspis, the adult female is completely enclosed within the nymphal pellicle, and it will be necessary to break this open (with a fine needle) to obtain the actual insect.

Insects of the genus Asterolecanium require very careful handling. The derm is exceedingly thin and delicate. A very short immersion in boiling potash is sufficient to soften the tissues and decompose the contents of the body. I find it best to place the complete scale in the potash and continue the boiling only until the secretionary matter is dissolved, when the insect-now freed from its covering - should be immediately transferred to distilled water.

The treatment must be modified when dealing with adult males of any of the smaller species. Boiling in potash results in the hopeless crumpling of the wings and their entanglement with the other limbs. For such delicate objects a more prolonged immersion in cold potassium hydrate is preferable.

The procedure may be roughly summarised as follows :

(1) Boil in potash for a few minutes, or immerse in cold potash for a longer period, until the contents of the body are completely softened.

(2) Soak in distilled water for 24 hours.

(3) Press out the softened contents, and clean the surface parts.

(4) Mount temporarily in dilute glycerine.

(5) Stain with fuchsin, for 24 hours.

(6) Fix stain with picric acid for 5 or 10 minutes.

(7) Wash and remove superfluous stain in $70 \%$ alcohol

(8) Wash in absolute alcohol.

(9) Place in oil of cloves for 10 minutes.

(10) Mount finally in canada balsam. 


\section{Preservation of Unmounted Specimens.}

A few hints for the preservation and storing of unmounted material may be of use.

Desiccation is the method usually adopted and-for a general collection-is certainly the most convenient; though, where it is desired to retain the exact form of the fresh insects, it may be advisable to preserve duplicates in alcohol or dilute formalin.

A very large number of species, e.g. all the Diaspidinae and the flatter forms of Lecanium, may be treated like botanical specimens, i.e. dried, together with the leaves to which they are attached, between absorbent paper. But the pressure employed should be light-merely sufficient to keep the leaves flat. I frequently have material submitted to me for determination, where no pressure at all has been employed, with the natural consequence that the leaves are so curled or shrivelled that the task of examination is greatly aggravated. In such cases it is necessary to break up the whole material and to examine it very closely or valuable specimens may be overlooked. A leaf that has been dried flat may be completely examined with the maximum of convenience in the minimum of time. Thin slices of bark, or rind of fruits, may be treated in the same way. Twigs bearing specimens may be cut up into convenient lengths and dried without pressure. In any case, superfluous and useless parts should first be removed, to facilitate subsequent examination and save space. Leaves bearing hemispherical or highly convex species may be dried flat without pressure by pinning down the edges. Species that are not habitually attached to their host plant, such as many species of Pseudococcus, Orthezia, etc., are best removed and dried separately, after which they may be kept in small glass tubes plugged with cotton wool, or, better still, in the small gelatine capsules supplied by chemists for the reception of various drugs. Specimens dried in situ should be wrapped in soft paper and placed in small envelopes upon which the full data should be written. Capsules or tubes should be placed in similar envelopes. The envelopes themselves may be conveniently stored in white cardboard boxes which should be made to order and should be of various sizes which must be multiples of the smallest unit. The sizes that $\mathrm{I}$ have adopted in my own collection are :

$$
\begin{array}{ll}
1 \frac{3}{4} \times 2 \frac{3}{4} \times \frac{1}{2} ; & 1_{4}^{3} \times 2 \frac{3}{4} \times 1 ; \\
1 \frac{3}{4} \times 2 \frac{3}{4} \times 2: & 1_{4}^{3} \times 2 \frac{3}{4} \times 4 .
\end{array}
$$


The drawers of my cabinet have an inside measurement of $17 \times 16$ $\times 2$ inches deep, each of which will hold six rows of $30,15,8$ or 4 boxes, according to the size. With the exception of the largest size, the boxes stand edgeways in the drawer.

Each box should be reserved for a single species only, but may contain several gatherings of that species. The name of each species should be clearly indicated on the cover of its particular box. The various genera will naturally be grouped in their respective families, but it will be found convenient to arrange the species alphabetically, under their respective genera. A small quantity of finelv powdered naphthalin should be placed in each box, and renewed periodically. If preferred, naphthalin dissolved in petrol or benzine may be employed. A few drops of this liquid will spread over the bottom of the box and, upon evaporation, will leave a fine deposit of naphthalin which has the advantage of not shifting its position when the boxes are placed on edge.

Specimens preserved in a liquid medium (for which alcohol of about $80 \%$ or formalin diluted to about $3 \%$ may be employed with satisfactory results) must be kept in tightly corked tubes. These do not lend themselves so conveniently to arrangement in the general collection. They must be stored in separate racks, or in boxes fitted with compartments for the purpose.

Glass slides with microscopical preparations can be stored in any of the various forms of boxes or cases designed for the purpose. I use cases made in book form, each case containing 50 slides, with an index on the inside of the cover. Such cases can be arranged like volumes on book shelves.

Surplus material should always be retained, for purposes of exchange. Great convenience and economy of time will be experienced if such duplicates are at once portioned out and placed in labelled envelopes, ready for distribution when required, instead of being stored in bulk. When an application for specified duplicates is made by some correspondent, the time required to go through a large collection, separate out the required material, do it up in packets and label it, is often greater than can be given at the time. The task is therefore postponed for some more favourable opportunity which may be indefinitely delayed. I keep all my duplicate material in small labelled envelopes which are stored (alphabetically) in tin boxes made especially to fit them. Any species can then be found instantly and is ready, without further attention, for distribution. 


\section{The Importance of Exact Measurements.}

Finally, I should like to say a few words on the importance of exact measurement in critical comparisons. For this purpose a camera lucida is almost indispensable. Take, for instance, the determination of the antennal formula. Direct measurement of such minute parts is extremely difficult; but, if enlarged camera drawings are made, they can be compared and measured with the greatest facility. Neither the eye alone, nor freehand drawings can be trusted implicitly. Body measurements alone are not of much value between clusely allied species, as individuals from a single colony often vary considerably in size, and such variability is still more marked between examples collected on different plants. But the more densely chitinous parts - antennae, limbs, anal lobes, etc. - are much more constant. After the final moult these organs do not increase in size, though the body of the insect may more than double its original dimensions. 


\section{$2 \mathrm{BHL}$ Biodiversity Heritage Library}

Green, Edward Ernest. 1914. "On the preparation of Coccidae for microscopical study." Annals of applied biology 1, 98-106.

https://doi.org/10.1111/j.1744-7348.1914.tb05414.x.

View This Item Online: https://www.biodiversitylibrary.org/item/33962

DOI: https://doi.org/10.1111/j.1744-7348.1914.tb05414.x

Permalink: https://www.biodiversitylibrary.org/partpdf/11929

\section{Holding Institution}

MBLWHOI Library

\section{Sponsored by}

MBLWHOI Library

\section{Copyright \& Reuse}

Copyright Status: NOT_IN_COPYRIGHT

This document was created from content at the Biodiversity Heritage Library, the world's largest open access digital library for biodiversity literature and archives. Visit BHL at https://www.biodiversitylibrary.org. 